The Sustainable City XV 51

\title{
HACKING THE NEXT MEXICAN TERRITORIES: HOW TO FACE THE “CRISIS” OF THE TERRITORIES AND THE GATED-COMMUNITIES' SYSTEM
}

\author{
EMANUELE GIORGI \\ Escuela de Arquitectura, Arte y Diseño, Tecnologico de Monterrey, Mexico
}

\begin{abstract}
The uncontrolled development of private gated communities (PGCs) in Mexican Territories is one of the many issues that are putting at risk the weak alliance between Humankind and Environment in our contemporary times. To change this trend, can design find a new ally in technological development? A diffused lack of human spirit seems characterizing contemporary society and territories, where decisions are controlled more by the economy and the technological development, rather than by the humanistic decision. This crisis is given by a lack of decision-making authority, but also by a widespread sense of fear and anxiety towards a technology-based environment, which is at the same time more and more powerful and less and less handleable. In this background, PGCs find a favourable context where to bloom and, even if they don't bring positive benefits to the cities, nowadays they represent a very common phenomenon in all the American territories. Base on literature review and analysis of contemporary cases of digital interaction among citizens-IoT-environment, this research aims to (1) promote a reflection on the role that the technological and economic systems play in the development of contemporary territories, with particular reference to the phenomenon of PGCs, (2) analyze which analogies can be observed between urban-architectural design and technology to (3) define some strategies for designing new sustainable communities "hacking" technology-based environments. If territories are a combination between physical and digital dimensions, hacking them means working in the digital space, impacting the physical one. Thanks to technological devices, available to everyone in the daily life, procedures of re-designing territories and hacking the existing systems can be considered as a participative, fast and ubiquitous practice.
\end{abstract}

Keywords: private gated communities, sustainable territories, technological development.

\section{INTRODUCTION}

The relationship between the design and the technological dimension is a cornerstone of our society, arriving to increasingly characterize the cities and the territories where we live [1][5]. These contemporary characteristics that, day by day, people are experiencing doesn't refer just to the technological dimension as a new set of devices that influence our days. In fact, the technological dimension of our territories implies, firstly, a necessary reflection on the effects that this new system has on our culture and on the social relations that are generated in the sphere of the built environment. Among these reflections, one of the most relevant concerns the sense of confusion that characterizes the Individual of today. All those changes that have affected the Humanity, since the first industrial revolution, are the main reasons for the bewilderment which the contemporary society is living today. From the strategies to tackle climate change, to the challenges of AI, from the contacts between the biological and the digital spheres, to the plans for the colonization of other planets, Humanity is facing dilemmas that never before have been so preponderant and real in the social debate. Moreover, faced with these dilemmas, Humanity finds difficult to catch, not only the answers, but even a method of reasoning. In fact, one of the main problems is the incapacity to develop a way of thinking which is different from the technical one, which is the predominant one today. Umberto Galimberti repeatedly reminds us of the thought of Martin Heidegger who, almost a century ago, warned about the current danger: "It is not disturbing 
that the world becomes a huge technical apparatus, much more disturbing is that we are not ready at all for this radical transformation of the world, but what is even more disturbing, and we are at the third degree, is that we do not have an alternative thought to the thought as a calculation" [6], [7]. In a world where development is driven more by the needs of economic and technological systems than human will, humanity seems lost in understanding the directions toward the future. A general sense of loss and "crisis" dominates the relationship between Humankind and his Environment. Even when the subject of the speech is the natural or the social environment humanity is experiencing the same problems: it remains uncertain how we should actually behave in front of the contemporary challenges. It's difficult that politics could take decision on how to feat climate change, deforestation, plastic in the seas, on how to redefine the role of traditional institutions, globalization, economic inequality, migration or technological development. According to Harari, the recent pandemic crisis shows how the political system lost the Covid-19 challenges, while the technology and science came out as the winners [8], [9]. In fact, the most important solution to the pandemic came from scientists who developed the vaccines.

In the twenty years old book "In Search of Politics", Zygmunt Bauman reminds us that "Today few remember that the word "crisis" was coined to designate the moment to make decisions. Etymologically, the word is much closer to the term "criterion" - the principle we apply to make the right decision - that to the family of words associated with "disaster" or "catastrophe", in which today we tend to place it" [10]. Before crises were overcome by the belief that the acquisition of knowledge would mean the disappearance of the crisis, now we are not able to know how to overcome the incapacity to take decisions. Bauman continues, "What today we call "crisis" is not only the state in which forces of a contrasting nature collide [...] but, above all, a state in which no emerging form seems destined to consolidate and survive for a long time. In other words, the "state of crisis" is not the same as the state of indecision, but rather the state of the impossibility of the decision" [10]. Indeed, society seams becoming less and less able to take the decisions it really needs. More generally, the current inability to make decisions is seen in the inability to implement, with a political effort, a change of direction towards new models of growth that do not require consumption of resources and energy, as the contemporary ones are doing (what is called "decoupling", for example) [11].

How can we do, if we do not want to resign ourselves to this situation and live in the Max Weber's "iron cage" [12]? How can we, as designers, develop a new design strategy? Can we exploit, for example, the technological dimension of the city, in which we are always immersed, sometimes even unconsciously?

\subsection{The modern territorial conception}

In 1760 the Catasto Teresiano (Fig. 1) was completed: it was an innovative system which mapped the landed properties in the State of Milan, based (and here is the innovative aspect) not on descriptions but on exact plans associated with information. Data such as the owner, the destination of use and the valuation allow to calculate the tax due to the State [13]. Here, the modern conception of organizing and interpreting the territory, based on elementary units described by parameters, born. This concept evolves more and more, up to the contemporary regulations that order the territory. Thus, the organization and the design of cities and territories is controlled by constraints, technicalities and market logic. The mathematical thought that at the time of the Renaissance had generated the image of the ideal city (whose representation, based on perspective and calculation, does not show the most important 


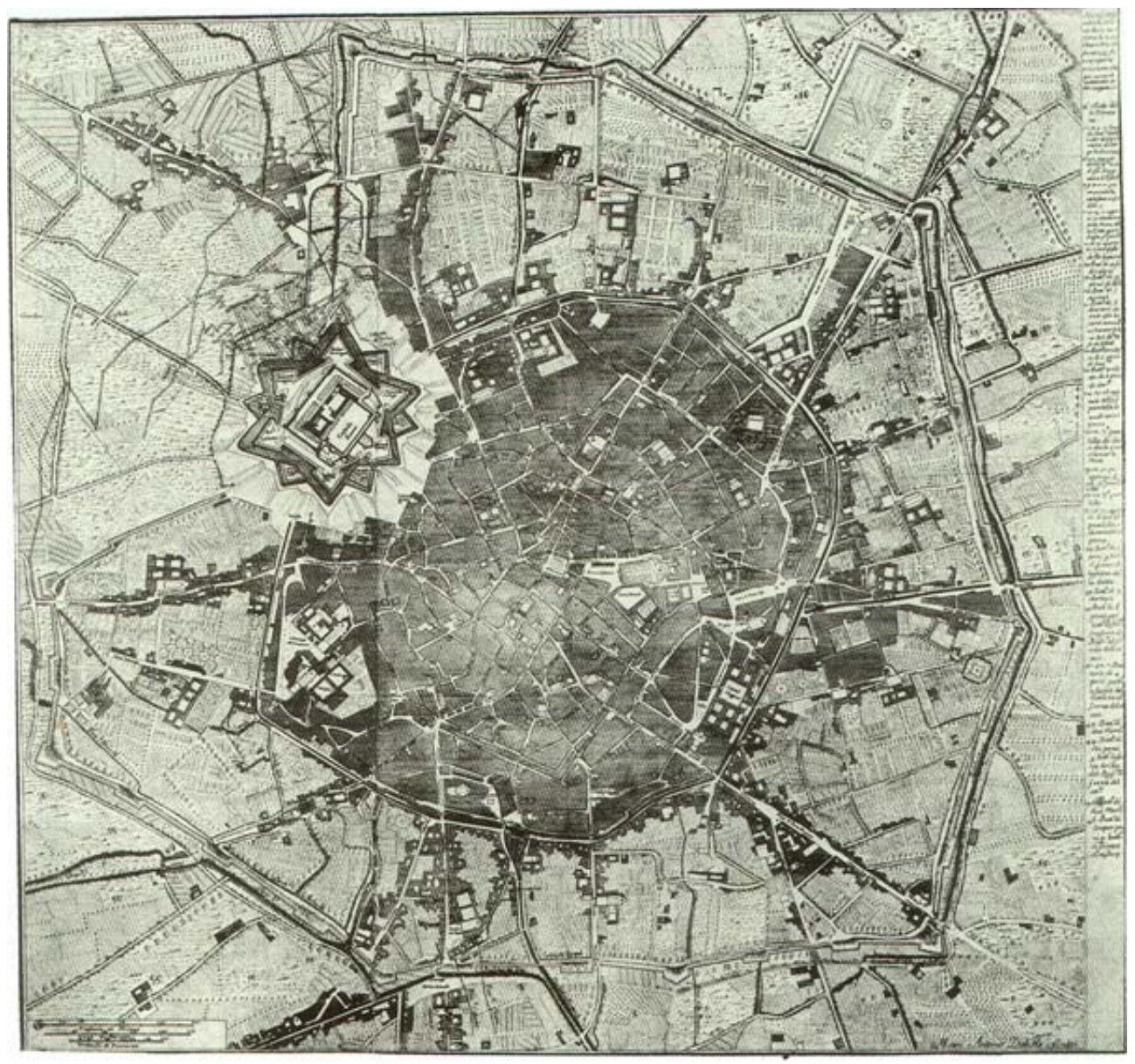

Figure 1: Marc'Antonio Dal Re (1697-1766), Map of Milan in 1734. Engraving. (Source: Wikimedia Commons $\{\{$ PD-Italy\}\}.)

aspect of the cities: the inhabitants) - has now led to technical regulations that are more careful to rationalize the territory and the complex urban systems rather than listening to the variable needs of Humankind and supporting his extraordinary creativity.

The fact that technology, today, surrounds us is something not to be explained. Cities are now territories where the physical dimension, the one of architecture and space, is linked indivisibly with the digital dimension, created by data and information that our smartphones generate, transmit, receive, store and retransmit continuously 24 hours per day [14]. It makes no sense trying to understand the contemporary urban phenomena without considering the technological network that dominates them with the "internet of things" and the "ubiquitous computing".

This topic is the source of the concern presented in this contribution: if society is in a state of crisis due to the incapacity to take decisions - and this is mainly due to the predominant role of technology in our contemporary world - can we exploit the widespread presence of the technology itself to bring back the Individual being the central role of the urban life, as 
promoter of territorial regeneration? Can the spread ability to handle technology become an ally for urban and architectural design? Can diffused technology become a resource for a sincere and diffused participatory design or a source of inspiration for truly contemporary projects and drivers of change?

\section{CRISIS AND COMMUNITIES}

Individualism, created by those economic and technological forces that generate that sense of crisis that we just investigated, is at the same time the main cause for the crisis of our territories, where the basic concept of "community", the fundamental unit of the social sustainability of a territory, is often endangered [15]-[17]. Humankind has always taken into consideration living in community as a basic element of social organization: the community goes from an elementary nucleus that protects a few individuals, to a much larger group of individuals who share a belief or ideals [18]. Since the development of language and imagination, Humankind has been able to organize itself into small groups that allowed it to develop a protected environment around their own components. Since the first tribes and the first City-states, humanity has always adopted this "strategical communitarian support" to continue its journey of the social evolution. Being expelled by the community was one of the worst punishments for a citizen, and the hermit, who turned away from the community on his own, was a unusual personality [19]. Moreover, each culture has developed housing solutions that allow its concept of community to develop in the physical world. There are examples all over the world that indicate how community buildings played a key role in the development of society, helping in flourishing internal relations, while protecting it from the external dangers that threatened it. The Tulou in the Fujian region, the European farms or the Aztec Calpulli are just some examples [20]. With the modern illusion of being able to do anything thanks to the technical skills, Humankind has forgotten this natural dimension of the community [17]. Moreover, the pushed individualism that distinguishes contemporary society has made the situation worse, pointing out how much the economic profit and a cold urban planning are far more important than the community dimension of the territory.

For the relevance of the phenomenon in these regions, we take as reference the reality of Mexican territories, in which the concept of community is facing a significant crisis in urban and social terms. This is mainly due to the urban phenomenon of the "fraccionamientos", or private gated communities (PGCs), which are becoming the predominant element in the urban development of Mexican territories. Basically, these PGCs are residential areas, closed by walls and fences, where the management of the main services is provided by private gestors [21]. This urban phenomenon, which is spreading all around Mexico, involves not only new residential settlements, but also the existing ones. In fact, residents of different parts of the cities decide often to close the public roads crossing their settlement, to erect walls and to place private access controls to ensure a stronger perception of security and, even, better urban services provided by private companies.

In the last years, this phenomenon grown up a lot, mainly for issues related to the perception of urban security and for the benefits that the public administrations can obtain not have to provide basic services in these areas, where residents pay private services (in addition to the taxes) [22]. Within this scenario, there is a strong economical speculation of construction companies and several implications for the territories (accessibility, traffic, social and fiscal boundaries, unwalkable cities, etc...). In the north part of León (Guanajuato, Mexico) the $30 \%$ of the territory is closed by this kind of settlements (Fig. 2) [22]. While they are an increasingly common phenomenon in the American territories, these PGCs do not always have positive effects for the cities, nor can they be considered sustainable urban solutions [23], [24]. Although many times policy makers, construction sector and the wider 
society do not realize, there are many negative impacts that these structures have on cities, such as social segregation, sectorization of the territory or urban disconnection. At the base of this phenomenon, there is a structured economic system, capable to respond to the growing perception of insecurity and that motivates the diffusion of this residential proposal that will increasingly characterize the next Mexican territories. However, the biggest problem is that the negative effects of the PGCs are not yet popularly perceived. Researchers from the School of Architecture, Art and Design of Tecnológico de Monterrey conducted a survey among inhabitants of the already mentioned northern areas of León. Of the 180 respondents, the $62 \%$ believe that this enclosure has no impact on cities and of the remaining $38 \%$, the majority believes that the impact is mainly positive than negative [25]. However, the reality is that, to allow the development of PGCs, several times, public streets are closed, complicating urban viability and increasing traffic, pollution and waste of time. Moreover, PGCs cut public spaces, which are the lymph of each city, and, even worse, increase the social disparity.

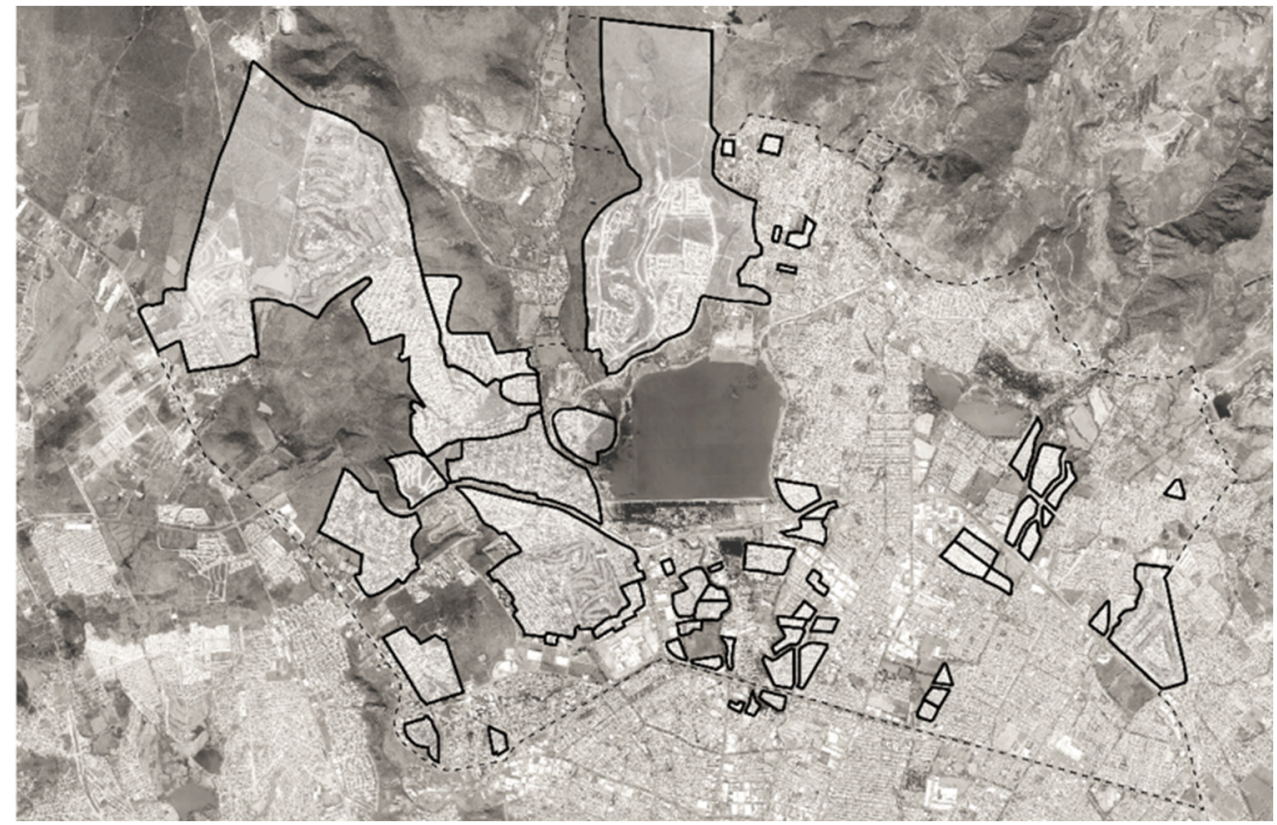

Figure 2: Northern region of Leon (Mexico) with the area closed by PGCs. (Source: Cristian Charles-Arenas and Paola Gutiérrez-Guerrero, 2017.)

For the importance of perception, it seems relevant to make here a very quick reference to the concept of "fear" in contemporary society. As Nan Ellin observes, the city has always been the place of safety, which, thanks to walls, ditches and gates, protected citizens from war and wilderness. But today, "from a place of relative security", the city has come to be associated, "more to the danger than to safety" [15]-[17]. The aforementioned Bauman highlights how this "demon" of the fear is spreading today in our cities, making it a phenomenon that grows stronger: "Once fallen in the world of men, fear feeds on its own, acquires its own logic of development, grows and spreads - in an unstoppable way - almost without need of care, of further contributions. [...] These are our reactions that transform the dark omens into everyday realities, making the word become flesh" [26]. 
As already mentioned, the main problem of these residential settlements is mainly the one of physically and perceptually division of the territory, with causes that mainly concern social equity, traffic and pollution. Anyway, it's very important to understand that the problem are not the PGCs, which appear to be a solution to the understandable and reasonable demand for services and security, but the way in which these settlements are designed and, in particular, the lack of relations they produce with the social tissue. Here is the core of the problem: the strong economic and social reasons that motivate the design of PGCs, contribute to create a system, which is very difficult to modify or disturb with traditional design instruments. In fact, it would not be possible to change the contemporary urban system with traditional tools because: (1) individual and community are experiencing a crisis in decision making and (2) the existing system rewards economic - utilitarian aspects rather than aspects of human simplicity and daily life.

This is the reason why the urban-architectural design must think in a new strategy, able to change existing systems and, in the case of Mexican Territories, to propose settlements that guarantee services and security, while, allowing a sustainable urban development.

The concern expressed at the beginning of the contribution is applied here, to this consideration: since these contemporary urban systems are too difficult to change in traditional ways, can the urban design take advantage from the contemporary condition of a ubiquitous technology, making it the tool to modify and to disturb all these existing unsustainable urban systems? Can ubiquitous technology be a new ally for design? Can the ubiquitous technology be the tool for the humanistic development of the next territories?

\section{HACKING}

Since this study aims to refer to the digital layers existing in our territories, the authors started the analysis looking at the information technology (IT) world, where, if someone wants to change an existing system, improving it and going over its actual possibilities, he needs to hack the system. Inspired by this digital dimension, where this practice of revolutionizing systems is habitual, the research affirms how rethinking the design strategies can allow the redesign of the built environment and lead to innovative solutions in the design of contemporary territories characterized by PGCs. As pointed out by Ratti [27], if in the digital world you want to change a system, there are three steps to follow:

1. Understand exactly how the system works;

2. Understand how to change the system;

3. Take possession of the system.

While this procedure of "hacking" can have a positive meaning if used to improve a system and test its defence capabilities, the term is often associated to criminal actions and, therefore, for the public opinion, the term "hacking" has a mainly negative connotation. For example, in "The Global Risks Report 2019" of the World Economic Forum [28], "Critical information infrastructure breakdown", "Cyber-attacks" and "Data fraud or theft" are considered as some of the most dangerous risks for these years, showing a high index of impact and likelihood. Furthermore, a 2016 CNBC article reported that estimated the existence, by 2020, of over 29 billion IoT endpoint devices: all potential victims of cyberattacks [29]. To have an idea of the phenomenon, according to Pablo Tamez, Chief Information Security Officer at the Tecnológico de Monterrey, this institution receives on average 2 million cyber-attacks per month, which are stopped by the cybersecurity team [30]. By the way, the term was born at the MIT in the early sixties, precisely in order to indicate the ability of some computer experts to go beyond the "conventional" capabilities of a program and thus allowing to improve its performance. In the panorama of possible 
definitions attributable to the "hacking" phenomenon, the most significant concept is the one that associates the term with the efforts of IT experts to defend privacy and the right to free information. In fact, the principle that define hacker communities is "sharing": the motto "Share your knowledge" means precisely this principle of behaviour according to which knowledge must be shared in order to achieve wellbeing and improve people's lives. Exactly this aspect of "sharing" is another element that highlights how significant is referring to "hacking" for the design of next territories: we need to hack Mexican territories to improve people's live, sharing communitarian belonging and social participation.

Hacking a territory means (1) taking possession of an existing physical system, like a public space that is the stage of urban phenomena, and (2) promoting new and different interactions between people and environment. Since the double essence of our territories, it can be done acting on the physical dimension or on the digital one. From the beheading of Louis XVI in Plaza de la Concorde, the square symbol of French Monarchy, to the revolts of the "Arab Spring", which took possession of the main public spaces of the involved capitals, squares, streets and icons have been the urban elements that, more than any other, adapt to physically "hack" a territory. Without thinking to the extreme cases of revolutions, let's try to reason on how technology can allow us to change urban spaces: how can technology allow us to reach more equitable territories, allowing each individual in a city to contribute in changing the social interactions spaces? Continuing to apply this thinking to the case of PGCs, so difficult to modify or disturb for the strong economic apparatus that impose and govern it, this opportunity to work digitally can allow to open a new front of work and to allow designing territories, where the PGCs would be not so much impacting in the physical and social environment. Considering the 3 steps, previously introduced, that define the hacking procedures [27], is possible to make a theoretical comparison with territorial dimensions. So, according to this principle:

(1) To understand how a territorial system works

Likewise hacking informatic systems brings principles of democratization and free access to information, in the cities, systems to map urban phenomena (traffic, contamination, temperature, people's congestion, etc.) allow people to understand how complex modern urban systems really work and, based on the received information, to develop a more precise awareness and to take proper decisions.

This step allows immediate and well-founded responses to complex management situations. For citizens, this translates into the possibility of making better real-time decisions on how to behave in the territory (for example, choosing the shortest way to get home based on existing traffic). For policy-makers, this process allows to take decisions about urban management in a more appropriate way, for example, by changing the location of ambulances during an event based on the concentration of people. This level essentially refers to understand how a system works and to take decisions that affect behavior or organization.

Too many times, the interactions between citizens and these new digital-physical territories stops at this first step, where technology influences just people's behaviours, without having the sufficient strength to bring the thinking to the deeper level to understand how to the urban system can be modified.

(2) Understand how to interact and to modify an urban system

The following step, forward to take just a decision that affects behaviour in the territory, is the possibility of developing an awareness of how to interact with the system, or how to modify some parts of it to allow better activities. This means defining which are the urban architectural elements that influence the system and how they influence it: geo-referencing in a map an urban phenomenon allows to understand which elements contribute to generate the phenomenon itself and permits to redesign the elements to modify the system. This 
activity undoubtedly concerns individual citizens, but in particular policy-makers and designers, who can be aware of what physical elements influence the urban phenomena, and in this way they can act in the physical world, modifying the system in the best possible way. While the first step allows to understand the system and to change personal behaviours according to the system, this second step allows to modify the system according to the desired behaviours. At the second level, the need to develop a sense of awareness about the phenomena, which are being generated in the territories, arises. Going to this level implies that we need to develop a consciousness on how to acquire and interpret the data that the digital network provides us.

(3) Take possession of the urban system

The deepest level is precisely the appropriation of the system: the awareness acquired by people is not limited only to producing physical changes in the territory, but also creates new interactions between the elements of the territory. Applications allow the users to provide comments in a democratic way, informing and organizing digital communities, up to contributing to the change of the urban space. If we think about the development of the IoT it is easier and easier to see individuals that, with computer tools, can easily interact with the environment and modify it. This step represents the complete integration of the individuals in the digital dimension of the territories and makes people able to interact, through the IoT, with the architectural urban elements, modifying the physical world in real time. At this third level of depth, awareness does not stop at the interaction with the built environment, but spreads among the elements that make up the built environment (people, IoT elements, physical urban elements, etc.) allowing a democratic management of the system itself. The democratic management of the system implies the possibility of discussing, making decisions and implementing in the two digital and physical dimensions.

In this sense, according to the potentialities expressed in these steps, hacking territories is:

Participatory: everyone can (1) generate data that allows to better understand the territory, (2) propose solutions to modify the physical world and (3) participate, as aware individual, to the sustainable urban life;

Fast: generation, communication and processing of data occurs in real time, as well as the resulting decision-making and their effects in the physical-digital environments that can be quickly visible;

Ubiquitous: these processes can happen anywhere in the territory, and they encourage the uniform development of the territories, from the wealthy urban neighbourhoods to the vulnerable rural communities.

\section{A HOPE}

This contribution aims to open a discussion about the possibilities that the contemporary territories, which are more and more technological, offer to solve the controversial contemporary urban phenomena. These urban phenomena represent, unfortunately, the impotence and insignificance of Humankind in front of contemporary challenges, where technology seems to embody more a dangerous issue than a saviour resource.

In particular, Mexican territories, characterized by individualism and a sense of fear, are well representative of this contemporary condition. Here, an easy, but worsening, answer is given by the PGCs, which increase the strength of the economic - political - normative system that is at the base of this unsustainable development. Considering that individual initiatives (by citizens, designers or even political parties) are unable to face and to modify this system as it is, it is absolutely urgent and necessary to find a new way to change the 
system of our territories. An interesting strategy could be offered precisely by the technological dimension, borrowing its ability to modify and to improve existing systems.

As analyzed and discussed, this would means being able to give people the opportunity to directly modify the physical world, allowing them to experience cities and realities in a new way. Thus, hacking territories can shape the environments of the future by modifying or disrupting, in a democratic and sustainable way, all those contemporary urban systems that today, although we do not realize it, affect our lives.

\section{ACKNOWLEDGEMENTS}

The author would like to thank the directors of the School of Architecture, Art and Design of Tecnologico de Monterrey (Mexico), who supported this research and provided interesting argumentations to enrich the discussion. Additionally, a special thank goes to Dr. Tiziano Cattaneo, Director of Environmental Futures Lab. at the College of Design and Innovation, Tongji University in Shanghai (China) who organized the Research Seminar "Environmental Futures: design and green technologies" where the very first ideas presented in this paper have been presented and discussed.

\section{REFERENCES}

[1] Yan, F., Liu, X., Chen, J. \& Lingxue, Y., China's wetland databases based on remote sensing technology. Chinese Geographical Science, 27, pp. 374-388, 2017.

[2] Navío-Marco, J., Rodrigo-Moya, B. \& Gerli, P., The rising importance of the "Smart territory" concept: Definition and implications. Land Use Policy, 99, 2020.

[3] Tai-hoon, K., Ramos, C. \& Sabah, M., Smart city and IoT. Future Generation Computer Systems, 76, pp. 159-162, 2017.

[4] Allam, Z. \& Newman, P., Redefining the smart city: Culture, metabolism and governance. Smart Cities, 1(1), pp. 4-25, 2018.

[5] Serrano, W., Digital systems in smart city and infrastructure: Digital as a service. Smart Cities, 1(1), pp. 134-154, 2018.

[6] Heideger M., L'abbandono, (1959), Il melangolo: Genova, Italy, p. 36, 1983.

[7] Galimberti, U., Psiche e techne, Feltrinelli: Milan, Italy, 2016.

[8] Financial Times, Yuval Noah Harari: Lessons from a year of Covid. www.ft.com/ content/f1b30f2c-84aa-4595-84f2-7816796d6841. Accessed on: 5 Mar. 2021.

[9] Berger, P.L. \& Luckmann, T., Modernity, Pluralism and the Crisis of Meaning: The Orientation of Modern Man, Bertelsmann Foundation Publishers: Gütersloh, Germany, 1995.

[10] Bauman, Z., In Search of Politics, Stanford University Press: Stanford, USA, 1999.

[11] Jackson, T., Prosperity Without Growth, Earthscan: New York, 2009.

[12] Mitzman, A., The Iron Cage. An Historical Interpretation of Max Weber, Transaction Book: New Brunswick, USA, 2002.

[13] Cartografia, Politecnico di Milano. www.biblio.polimi.it/strumenti/cartografia. Accessed on: 14 Apr. 2021.

[14] Ratti, C., Architettura Open Source, Verso una Progettazione Aperta, Einaudi: Torino, Italy, 2014.

[15] Ellin, N., Slash city. Lotus International, 110, pp. 58-72, 2001.

[16] Sheila, F. \& Christian, I., The city as a commons. Yale Law Policy Review, 34, pp. 281-349, 2016.

[17] Bauman, Z., Trust and fear in the cities. Proceedings of the Conference Trust and Fear in the Cities, Bruno Mondadori: Milano, Italy, 2004. 
[18] Harari Y.N., Da Animali a dei, Breve Storia Dell'umanità, Bompiani: Milano, Italy, 2014.

[19] Brock, B. \& Haslam, N., Excluded from humanity: The dehumanizing effects of social ostracism. Journal of Experimental Social Psychology, 46(1), pp. 107-113, 2010.

[20] Giorgi, E., The Co-Housing Phenomenon: Environmental Alliance in Time of Changes, Springer Nature: Cham, Switzerland, 2020.

[21] Klaufus, C., Van Lindert, P., Van Noorloos, F. \& Steel, G., All-inclusiveness versus exclusion: Urban project development in Latin America and Africa. Sustainability, 9(11), 2017.

[22] Charles C. et al., A quién pertenece la ciudad? Movilización, espacio publico, tejido social y bienestar: La privatización de calles en la zona norte de la ciudad de león. Entretextos, 3, 2017.

[23] Mahgoub, Y. \& Khalfani, F., Sustainability of gated communities in developing countries. Developing Country Studies, 2(6), 2012.

[24] Bagaeen, S. \& Uduku, O. (eds), Gated Communities. Social Sustainability in Contemporary and Historical Gated Developments, Routledge: Abingdon, 2012.

[25] Giorgi, E. \& Barquero, V., Proliferación de los fraccionamientos cerrados y sus razones de ser: descifrando el mito de seguridad y exclusividad. 4a Bienal Territorios en Movimiento, Universidad de Guanajuato, Campus León, México, 15 Nov., 2018.

[26] Bauman, Z., Il Demone Della Paura, Editori Laterza: Aquila, Italy, 2014.

[27] Ratti, C., La Città di Domani. Come le Reti Stanno Cambiando il Futuro Urbano, Giulio Einaudi editore: Trino, Italy, 2017.

[28] World Economic Forum, The Global Risks Report 2019. www3.weforum.org/docs/ WEF_Global_Risks_Report_2019.pdf. Accessed on: 12 Dec. 2020.

[29] CNBC, The next big threat in hacking - data sabotage. www.cnbc.com/9Mar.2016/ the-next-big-threat-in-hacking--data-sabotage.html. Accessed on: 10 Sep. 2020.

[30] La ciberguerra: Riesgo del siglo XXI por las instituciones y empresas. Conecta. https://tec.mx/es/noticias/nacional/institucion/la-ciberguerra-riesgo-del-siglo-xxipara-las-instituciones-y-empresas. Accessed on: 14 Sep. 2020. 